\title{
APOIO MATRICIAL: UMA EXPERIÊNCIA DA RESIDÊNCIA MULTIPROFISSIONAL EM SAÚDE
}

\author{
MATRIX SUPPORT: AN EXPERIENCE OF MULTI-PROFESSIONAL RESIDENCE IN HEALTH
}

APOYO MATRICIAL:UNA EXPERIENCIA DE LA RESIDENCIA MULTIPROFESIONAL EN SALUD

\author{
Aline Barreto de Almeida Nordi ${ }^{1}$ \\ Geovani Gurgel Aciole ${ }^{2}$
}

Resumo O trabalho aqui apresentado resultou de pesquisa documental, entrevistas semiestruturadas e grupo focal com as equipes de saúde, os apoiadores residentes e a gestão da atenção básica sobre a experiência de articulação entre as equipes de apoio matricial e referência em unidades de saúde da família, no contexto da reformulação do modelo assistencial em implantação em um município do interior paulista, no primeiro semestre de 2009. Os autores refletiram sobre a experiência com base em três dimensões: a compreensão inicial da proposta, o cotidiano de trabalho e os impactos no processo de trabalho do apoio matricial. Verificou-se que o apoio matricial apresentou problemas de entendimento da proposta e enfrentou a predominância de práticas curativas biologicistas e limites em relação à solução dos problemas da população. A integração entre os profissionais possibilitou pactuações conjuntas, o trabalho interdisciplinar e a construção de projetos terapêuticos comuns, ensejando perspectivas promissoras. Esperamos que esses achados subsidiem as discussões atuais sobre o planejamento e a gestão do apoio matricial no sistema local de saúde.

Palavras-chave Estratégia Saúde da Família; atenção primária à saúde; atitude do pessoal de saúde; promoção da saúde; saúde pública.
Abstract The work presented here resulted from document research, semi-structured interviews, and focus groups with health teams, resident supporters, and primary care management on the joint experience between the matrix support and reference teams at family health units in the context of the reformulation of the care model being implemented in a municipality in the state of São Paulo in the first half of 2009. The authors reflected on the experience based on three dimensions: The initial understanding of the proposal, daily work, and the impact on the matrix support work process. It was found that there were proposal-understanding issues in the matrix support and that it came up against the predominance of biological healing practices and limits with regard to solving the population's problems. The integration among professionals enabled joint pacts, interdisciplinary work, and the construction of common therapeutic projects, allowing for promising prospects. We hope that these findings subsidize the current discussions on the planning and management of the matrix support in the local health system.

Keywords Family Health Strategy; primary health care; attitude of the health personnel; health promotion; public health. 


\section{Introdução}

No Brasil, a atenção primária à saúde (APS) se direciona em busca de uma reorientação do modelo de cuidado dentro do Sistema Único de Saúde (SUS), sendo a Estratégia Saúde da Família (ESF) a organização estruturante (Brasil, 2012). As práticas e ações dos profissionais de saúde na APS buscam alcançar princípios fundamentais, dentre eles a garantia da integralidade, a produção do cuidado e o trabalho interdisciplinar, considerados importantes nós críticos a serem equacionados (Brasil, 2012; Machado et al., 2004; Escorel et al., 2007).

A integralidade se configura como um conjunto articulado de ações e serviços de saúde preventivos, curativos, individuais e coletivos, em todos os níveis de complexidade do sistema de saúde brasileiro (Brasil, 2012; Pinheiro e Luz, 2003). O cuidado é caracterizado como uma compreensão filosófica e uma atitude prática referente a uma ação integral, que mostra projetos terapêuticos em que a relação profissional-paciente seja dialógica, em busca de um tratamento relevante e viável (Ayres, 2001, 2004; Pinheiro e Guizardi, 2006). Tal entendimento significa a abordagem do indivíduo compreendida no contexto familiar e social no qual está inserido (Alves, 2005; Campos, 2003, 2007; Mattos, 2001, 2004).

A equipe multiprofissional é considerada um importante pressuposto para a reorganização do processo de trabalho no âmbito da ESF, visando a um cuidado mais integral e resolutivo (Silva e Trad, 2005; Escóssia, 2009). O trabalho em equipe é composto das práticas profissionais com diferentes recortes epistêmicos e execuções clínicas. Compreende as limitações de qualquer recorte, tanto para exercer uma clínica da atenção integral quanto para apreender as conexões que um quadro fisiopatológico ou psicossocial estabelece - modos de acolher ou reagir à vida operados por uma equipe colocada ante o desafio de responder às necessidades concretas de saúde dos usuários (Ceccim, 2004) e tornada demanda socialmente construída para os serviços (Franco e Merhy, 2005; Lacerda e Valla, 2005).

Como forma de ampliar as possibilidades de proporcionar um cuidado integral e integração dialógica entre distintas especialidades e profissões, discutiu-se a metodologia de gestão do cuidado em equipes de referência e apoio matricial, mais especificamente na ESF pelos núcleos de apoio à saúde da família (Nasfs) (Brasil, 2008).

O apoio matricial em saúde objetiva assegurar retaguarda especializada e suporte técnico-pedagógico às equipes e profissionais da atenção primária à saúde - as equipes de referência - mediante a construção de um projeto terapêutico integrado. Para contribuir com intervenções que aumentem a capacidade resolutiva da equipe, o projeto terapêutico deve reunir atendimentos individuais ou intervenções conjuntas entre o especialista matricial 
e os profissionais da equipe. Em situações que exijam atenção específica ao núcleo de saber do apoiador, este pode programar atendimentos ou intervenções especializadas; mas deve sempre induzir à troca de conhecimento e de orientações inter e intra equipe/apoiador (Campos e Domitti, 2007).

Com base nesses pressupostos, estudamos a experiência de apoio matricial nas unidades de saúde da família (USFs) do município de São Carlos, no estado de São Paulo, pela residência multiprofissional, após um ano e seis meses da sua implementação. Buscamos evidências de articulação entre ações e interação entre os apoiadores e a equipe de referência, assim como fatores que facilitaram ou dificultaram a construção dessa nova organização do trabalho em saúde naquele município. Este artigo foi elaborado com base na experiência da autora como residente do Programa de Residência Multiprofissional em Saúde da Família e Comunidade da Universidade Federal de São Carlos.

\section{Estudo qualitativo e relato analítico da experiência vivida}

Optamos pela abordagem qualitativa, pois esta considera a ação humana significativa, evidencia um compromisso ético na forma de respeito e de fidelidade em relação à experiência de vida e enfatiza a contribuição da subjetividade humana (intenção) em relação ao conhecimento (Schwandt, 2006). Trabalhar qualitativamente implica entender/interpretar os sentidos e significações que uma pessoa dá aos fenômenos em foco em que são valorizados o contato pessoal e os elementos do setting natural dos sujeitos (Turato, 2003). Trata-se, também, de um estudo de processo, o que reforça a escolha metodológica pelas seguintes características: aumentar o entendimento sobre fenômenos sociais complexos; esclarecer por que e como determinada decisão ou conjunto de decisões foram tomadas; evidenciar ligações causais entre intervenções e situações de vida real; ressaltar o contexto em que uma intervenção ocorreu, demonstrando o rumo de uma intervenção em curso e como modificá-la (Minayo et al., 2005).

Na pesquisa aqui apresentada, desenvolvemos um estudo qualitativo que construiu um relato analítico da experiência vivida (Minayo, 2006; Brevidelli e De Domenico, 2006; Santos, 2002) com base nos seguintes aspectos: a compreensão da proposta de apoio pelos participantes, a construção do apoio no cotidiano e os impactos no processo de trabalho pelo apoio matricial.

A coleta de dados foi realizada em quatro USFs de São Carlos, após aprovação pela Secretaria Municipal de Saúde. A organização do município relacionava uma equipe de apoio matricial para cada duas unidades de saúde da família. A seleção amostral seguiu os seguintes critérios de inclusão: a equipe de saúde teria de estar vinculada a uma equipe de apoio 
matricial há pelo menos um ano e aceitar participar da pesquisa. Foi excluída uma USF, aquela em que a pesquisadora atuou como apoiadora matricial. Com esses critérios, puderam ser pesquisadas oito USFs. Destas, foram definidas quatro, considerando-se a representatividade geográfica dos quatro territórios administrativos da saúde no município, contemplando-se apenas uma USF para cada equipe de apoio matricial.

Utilizamos os seguintes procedimentos para essa investigação: pesquisa documental, entrevista e grupo focal. A pesquisa documental teve como objetivo contextualizar historicamente e obter informações acerca de princípios e diretrizes seguidos, pactos, planejamento e ações desenvolvidas, todos formalizados nos documentos escritos produzidos pelas equipes pesquisadas (referência e matricial). Além disso, utilizamos os documentos para fazer contrapontos e associações com os outros materiais empíricos. As fontes pesquisadas foram: documentos institucionais (atas de reuniões, termos de referência, projetos formais das experiências com a Secretaria Municipal de Saúde e outros órgãos intersetoriais) e relatos de experiência (banners, artigos, cartilhas etc.).

Realizamos entrevista com o gestor da atenção básica de São Carlos, informante privilegiado em razão de seu poder decisório no processo de implantação e implementação do apoio matricial na saúde da família do município estudado. A entrevista foi elaborada em forma de roteiro para uma conversa com finalidade (Minayo, 2006). A utilização desta técnica permite que a direção da entrevista possa ser dada alternadamente pelo entrevistador ou pelo entrevistado, representando ganho para reunir os dados segundo os objetivos propostos (Turato, 2003). Na entrevista, foram abordados os seguintes temas: processo decisório para ampliação da equipe mínima nas USFs; arranjo organizacional em equipe de referência/apoio matricial; contribuições da equipe matricial nas ações de cuidado; avaliação da implantação do matriciamento no município.

O grupo focal reuniu os participantes em grupo para discussão de opiniões e ideias voltadas para o interesse da pesquisa. A relevância desse recurso metodológico está na capacidade de interação com o grupo e da coordenação da discussão (Cruz Neto, 2004). O grupo focal foi composto pelo segmento da equipe das USFs (equipe mínima) e a equipe de apoio matricial (assistente social, educador físico, farmacêutico, fisioterapeuta, fonoaudiólogo, nutricionista, psicólogo e terapeuta ocupacional), com duração de aproximadamente duas horas. Destacamos que a equipe matricial não estava presente com todos os seus membros nas reuniões da equipe mínima, devido à organização do trabalho de matriciamento em duas USFs.

Procuramos apreender, com base nas falas, como as equipes lidaram com os desafios da nova forma de organização e gestão do trabalho em saúde trazida pela proposta de apoiadores matriciais. O roteiro da facilitação do 
grupo foi composto pelos seguintes temas: ações oferecidas aos usuários; trabalho em equipe; cotidiano de trabalho; entendimento do apoio matricial. Realizou-se a facilitação por um moderador e um anotador, ambos com tarefas definidas antecipadamente. O dia e o horário da coleta de dados foram pactuados com a equipe em dia de reunião. Ao se contrastarem as representações dos profissionais das equipes e do gestor (categorias empíricas), pretendeu-se configurar as relações existentes entre os limites e as potências da implementação da proposta do apoio matricial nas USFs.

Para a organização do material coletado, utilizamos a abordagem hermenêutico-dialética. 'Beber da fonte' da hermenêutico-dialética é potente para correlacionar as diversidades múltiplas, do singular ao plural, no que tange, por exemplo, à articulação de equipes de apoio e equipes matriciais, pois enquanto a hermenêutica trabalha com a comunicação da vida cotidiana e do senso comum, entendendo o ser humano como ser histórico e finito, a dialética se traduz numa forma de abordagem crítica que busca desvendar as relações múltiplas e diversificadas das coisas entre si; explicar o desenvolvimento do fenômeno dentro de sua própria lógica; evidenciar a contradição interna do fenômeno; compreender o movimento de unidade dos contrários; trabalhar com a unidade de análise e da síntese numa totalização das partes; correlacionar as atividades e as relações (Minayo, 2006).

No contexto pesquisado, os entrevistados eram profissionais de saúde de diferentes categorias e formações num cenário de trabalho em saúde calcado em base interdisciplinar. Acreditamos que as falas dos sujeitos vêm imbuídas de subjetividades, da forma como entendem o seu trabalho e o do outro, mediante sua visão de mundo. Além do dito, há que se compreender em que situação histórica e social cada fala se contextualiza, no que tem de ressonância e no que tem de divergência no município estudado.

A operacionalização da análise foi realizada por meio de três passos: ordenação dos dados - foi realizada sistematização do material empírico obtido na leitura de documentos, nas entrevistas e nos grupos focais, seguindo as categorias estabelecidas antes do trabalho de campo; classificação dos dados com base no entrecruzamento do material empírico e das categorias previamente estabelecidas, identificou-se o que surgiu de temas relevantes: fragmentação do cuidado, necessidades de saúde, visão biologicista, rede de saúde, processo de trabalho, equipe multiprofissional/interdisciplinar, relações interpessoais, dificuldades encontradas (limites), ações desenvolvidas (potências); e relato final - por meio do qual procuramos estabelecer articulações entre o material empírico do caso particular e os subsídios crítico-reflexivos de referenciais teóricos do campo da saúde coletiva.

Todos os sujeitos pesquisados assinaram o termo de consentimento livre e esclarecido previamente aprovado pelo Comitê de Ética em Pesquisa com Seres Humanos da Universidade Federal de São Carlos (CEP-UFSCar), 
de acordo com o processo n. 248/2008, dentro de pesquisa de acompanhamento e análise da Residência Multiprofissional em Saúde.

\section{O 'cenário' da experiência}

São Carlos é um município brasileiro localizado no interior do estado de São Paulo, com população estimada em 212.956 habitantes. A rede de APS estava constituída de dez unidades básicas de saúde e 12 USFs. A população coberta pela ESF era de aproximadamente $25 \%$. O arranjo organizacional do trabalho das USFs se dá na forma de equipes de referência e apoio matricial (São Carlos, 2007). Entre as 12 unidades de saúde da família, havia seis equipes de apoio matricial, com a proporção de uma equipe matricial para duas USFs. Este formato tornou-se possível devido ao Programa de Residência Multiprofissional em Saúde da Família e Comunidade, que se constitui em ensino de pós-graduação lato sensu, na forma de curso de especialização caracterizado por ensino em serviço. O programa foi desenvolvido em parceria com a UFSCar e a Secretaria Municipal de Saúde, por meio da organização da Rede-Escola de Cuidado à Saúde do município.

\section{0 apoio matricial: primeiros entendimentos acerca da proposta}

A inserção dos residentes nas USFs, na forma de apoiadores matriciais, teve início em abril de 2007, coincidindo com um movimento de mudanças organizacionais e de gestão do trabalho na rede local de saúde e na APS em particular, cujo marco era a ampliação das práticas de saúde e sua qualificação em termos de processo de gestão e produção do cuidado.

Tal processo de reorganização se alimentou do diagnóstico gerencial de que havia excesso de demandas e cuidado centrado em patologias; a organização do trabalho dificultava a construção de vínculo e outras atitudes como humanização, corresponsabilidade e humanização das práticas de saúde; e existia forte hierarquização na gestão do trabalho, com frágil definição de responsabilidades clínicas ou sanitárias dos serviços. Eram aspectos que, somados, evidenciavam a fragmentação do cuidado (São Carlos, 2007). Entre as equipes, persistia uma sensação de distância entre o planejamento e a tomada de decisões concernentes à execução. Nesse hiato, as atividades desenvolvidas pelas equipes estavam mais voltadas aos interesses corporativos dos profissionais do que às necessidades dos usuários.

A chegada dos residentes, nesse contexto, foi marcada pelo desconhecimento de como o trabalho de apoio seria realizado, tanto pela dificuldade de cada profissão reconhecer suas práticas na APS quanto pela dificuldade das 
equipes de saúde em romper com o predomínio dos interesses corporativos ou burocráticos, para dialogar e definir um plano de trabalho conjunto. Outra dificuldade foi o fato de que as equipes de apoio matricial dividiam o tempo de trabalho semanal entre duas equipes, além da formação dos residentes envolver atividades teóricas fora dos serviços. Eram fatos que contribuíam para uma sensação de distanciamento e dificuldade de integração.

Alguns relatos retrataram, com precisão, tais dificuldades:

O começo foi terrível. Eles chegaram, são os poderosos. Era mais fácil falar com o doutor do que falar com eles (Agente comunitário de saúde 1).

Acesso aos profissionais foi muito difícil, não deram abertura, ajuda (Auxiliar de enfermagem 2).

Esse argumento seria reforçado pelo fato de que para as equipes de referência a chegada dos apoiadores teria acontecido como quem cai de paraquedas no lugar, o que legou ao trabalho de apoio a característica de não ser considerado atividade intrínseca ao processo de cuidado e acabou por fazer dos profissionais apoiadores uma espécie de outsiders para as equipes de saúde. Por um bom tempo, alguns deles tiveram recusada a participação nas reuniões de equipe, com o argumento de que "não faziam parte da equipe e que, por isso, não havia a necessidade de estarem presentes nas reuniões".

Ao mesmo tempo, havia equipes de referência que não estavam completas ou definidas. Em algumas USFs, era o espaço físico compartilhado por duas equipes que dificultava a realização do apoio, pois havia conflitos entre os profissionais que lá atuavam com relação ao uso do espaço. Nesse particular, nem equipe nem residentes souberam como negociar a construção do apoio matricial. Esse caldo institucional, em que se operava um movimento de mudança e apareciam as insuficiências e os déficits infraestruturais do sistema de saúde, ensejou, certamente, a produção de visões acerca do projeto, como a seguinte:

O apoio matricial foi igual a um brinquedo. Ganhamos um ótimo brinquedo para a gente brincar, só que não sabemos usar e também não veio com manual de instruções (Agente comunitário de saúde 5).

O gestor, por seu turno, reconhecia ter havido uma inserção conturbada, não do jeito que gostaria. Considerou que a residência foi uma estratégia de convencimento das equipes mesmo sem ter recursos; de fazer entender que isso qualificaria o cuidado na ESF; de que era necessária a ampliação das equipes com outros profissionais. No entanto, vislumbrou avanços no processo de trabalho das equipes, embora quando avaliamos a visão desses 
profissionais tenhamos percebido um hiato entre as intenções do gestor, os gestos da equipe e seu encontro com as necessidades sentidas e divulgadas pela população assistida.

É preciso trabalhar a autoestima da equipe, que está baixa, em relação à população. A equipe matricial chegou, e o que é esta coisa? Vendemos o 'peixe' errado do matriciamento (Agente comunitário de saúde 3).

(...) a população não entende que os profissionais que chegaram não vão ficar fazendo atendimentos (Enfermeira 1).

(...) o usuário quer o atendimento com o profissional (Auxiliar de enfermagem 4).

(...) a população sabe que tem os profissionais e procuram, querem o serviço (Médico 1).

Esse conjunto de afirmações deixou patente que a necessidade reclamada era a da atenção à demanda, ao passo que a proposta de matriciamento, ou melhor, de sua inserção nas práticas de gestão, era vista pelo governante como 'estratégia de convencimento das equipes' - descompasso que gerou interpretações e formas de atuação distintas em relação ao que os usuários e os profissionais tinham como visão comum para o desempenho do (e no) serviço. Essa dicotomia entre praticar a assistência e apoiar a equipe imobilizou ou comprometeu a ampliação do cuidado da família na direção das intenções pretendidas.

$\mathrm{O}$ fato de ter sido o primeiro ano de implantação do matriciamento respaldou, de certa forma, a possibilidade de experimentações e que cada local tivesse desenhada sua identidade. Aqui, novamente, abriu-se um hiato nas visões com que cada ator - gestor, equipes de referência e apoiadores examinava o cenário de atuação. As equipes de referência entendiam que muitas vezes traziam situações fora da competência da equipe de matriciamento - isto é, em boa medida, admitiam que desconheciam os limites desse papel/função no cotidiano dos serviços. O gestor, por sua vez, considerava sua avaliação com base em um lugar-comum sobre a atenção básica: o que definia para esse nível de atenção um grau mínimo de resolutividade, sem quaisquer evidências ou fatos que a sustentassem.

(...) tinha-se a ideia que a equipe mínima daria conta dos $85 \%$ dos problemas da população. Aí viu que não é bem assim. A equipe tem problema de ter resolutividade e começou a repensar essa lógica (Gestor X).

Em defesa da sua 'estratégia', o gestor advogou outros lugares-comuns: que com a inserção do apoio matricial esperava obter um cuidado mais integral; 
que a equipe conseguiria avançar e aumentar o grau de resolutividade; que a presença da equipe de apoio matricial na ESF proporcionaria aumento da acessibilidade e da resolutividade de queixas, anteriormente apenas medicalizadas. Assim, se diminuiriam o encaminhamento para outros serviços e o 'vaivém' do usuário na rede. Ainda segundo esse ator, a escolha do arranjo organizacional em matriciamento obrigava as equipes a pensarem na necessidade de unir esforços de todos os membros, discutir e sistematizar planos de cuidado, levando em consideração a realidade do cotidiano de trabalho, na qual não há presença da equipe de apoio todos os dias na unidade. Ele diagnosticava, enfim, que as equipes de referência trabalhavam em um processo em que ainda predominavam a cura e a assistência, e era este seu mais forte desejo de mudança.

Os apoiadores entenderam o apoio como ideia interessante como troca de saberes e proposta de garantia da integralidade do cuidado aos usuários e suas famílias; e também como forma de se ter uma retaguarda para a equipe de referência da unidade em diversos casos, tanto na assistência quanto no suporte teórico-pedagógico e na capacitação aos profissionais da referência. Aqui se mostrou forte o também lugar-comum que ecoa as intenções enunciadas pela literatura a respeito dos papéis e funções desempenhados pelo apoio matricial. Pela carência de serviços na rede, por exemplo, o matriciamento precisou muitas vezes atuar nos moldes do nível secundário, realizando atendimentos ambulatoriais dentro da USF.

A equipe de referência relatou que alguns ganhos foram conquistados, como a aproximação cotidiana juntamente com a equipe, e que os conflitos foram necessários. Pontuou também a importância de que a equipe de apoio se incorporasse mais ativamente e que a relação tomasse um caminho bidirecional entre apoio e referência.

A avaliação do primeiro ano feita por todos os atores foi empírica e se baseou na afirmativa de que a população reconheceu as melhoras, especialmente nas ações de prevenção e promoção de saúde. Nenhum deles apresentou provas evidentes de como foi feito esse reconhecimento, nem por quais processos ele foi percebido.

\section{O cotidiano do trabalho}

No início do trabalho de matriciamento nas USFs, houve maior demanda de encaminhamentos para avaliação específica dos apoiadores, pois para os profissionais das equipes era fundamental aliviar a agenda médica, bem como diminuir a demanda reprimida que havia sido encaminhada para o centro de especialidades. 
A expectativa era de que os profissionais fossem fazer em casa, mas os ACSs [agentes comunitários de saúde] é que fazem depois de ser capacitados pelo matricial. E quem sofre é a gente que está na 'comissão de frente' (Auxiliar de enfermagem 3).

Apoio matricial deve arregaçar as mangas e atender também. O médico tem seu núcleo, não pode atender tudo. O apoio não pode devolver tudo para o médico (Médico 4).

Paradoxalmente, para os profissionais o que acabou ocorrendo foi o aumento da demanda após a chegada dos apoiadores. Um aumento que carregou forte significado ambíguo. Por um lado, foi visto como positivo e permitiu reconhecer a presença dos residentes, tanto pelo profissional médico - pois "a atuação dos profissionais é boa porque amplia o leque de atendimento aos pacientes, mas amplia também minha demanda" - quanto pelo agente comunitário de saúde (ACS), ao perceber que "os usuários ouviram falar que outros atendimentos e atividades estavam sendo realizados e com isso até a demanda fora da área aumentou". Por outro lado, para os apoiadores houve dificuldades de interação com a referência no planejamento de atividades coletivas, pelo fato de não conseguirem 'dar conta' da demanda. Afinal, a atuação em APS carrega uma diversidade de problemas que devem ser equacionados e, em alguns casos, sufocam os trabalhadores pela quantidade.

Diante das mudanças no cotidiano do trabalho, as equipes de referência sentiram a necessidade de discutir novas formas de acionar o apoio para a resolução dos casos. Os apoiadores, por sua vez, argumentaram sobre a necessidade de um 'espaço' de matriciamento na reunião de equipe, para possibilitar um incremento de autonomia dela na resolução dos problemas. Em algumas USFs, o apoio passou a ser ofertado no espaço formal de reunião; em outras, essa incorporação do apoio se delineou no fato de as equipes perceberem que havia esforços reais para superar barreiras e distanciamentos. Alguns atendimentos e visitas domiciliares (VDs) estavam sendo realizados em conjunto; havia tentativas incipientes de formulação coletiva de planos de cuidado, além de reuniões de discussões de casos semanais.

\section{0 trabalho em saúde}

No que se refere ao trabalho em saúde, a inter-relação pessoal e profissional entre os trabalhadores foi fator preponderante relatado pelos participantes. Com a ampliação no número de profissionais e nas mudanças da organização do trabalho em referência e apoio matricial, essa recente organização inter- 
disciplinar mostrou-se ainda mais frágil e conflituosa. De início, a atuação entre as equipes apresentou-se dicotômica, ou seja, gerou fragmentação em dois ou mais segmentos trabalhando no mesmo espaço físico, aproximados de acordo com a atuação profissional.

Outros olhares se orientaram pelos ganhos e dificuldades ao longo do tempo no processo de trabalho. Foi relatado que os apoiadores aumentaram o arsenal de conhecimentos da equipe de referência para sua utilização em avaliações, atendimentos e interconsultas. Entretanto, a angústia de alguns membros da equipe em "agora ter que fazer o que o outro profissional deveria fazer" mostrou que essa construção ainda não tinha significado concreto e preciso para todos.

Ao ser instado a comentar o trabalho em saúde desenvolvido pelas equipes do estudo, o gestor relatou que muitos desses embates aconteciam em razão de a relação do apoio não ser vista como profissional, por sua inserção como residentes, e que os conflitos presentes faziam parte do processo de mudança e da busca pela qualificação do cuidado na ESF. No cotidiano vivenciado, os enfrentamentos e as soluções eram processuais e diferenciados em cada equipe. Algumas demonstraram ganhos, mas em sua maioria ainda estavam se ajustando após a chegada e a permanência dos apoiadores.

Para ilustrar os ganhos de aceitação, a legitimação do apoio no processo de trabalho mostrou-se mais diluída, o que não quer dizer que tenha sido discutida e enfrentada. Uma vez que nem todos têm, necessariamente, os mesmos objetivos e intenções ou fins, é nesse encontro de diversidade de opiniões que se gera o conflito. O conflito pode ser um grande revelador das questões do poder, suas imposições e opressões de valores e intenções presentes cotidianamente no trabalho em saúde. Por sua vez, a potência da interação dos diferentes pode contribuir para um cuidado com olhares e saberes diversos e igualmente importantes.

\section{Considerações finais}

O avanço e a consolidação do SUS vêm se tornando mais que a garantia de uma rede de serviços que ofereça assistência de qualidade. Têm feito desse sistema um instrumento e espaço de produção de saúde que opera no atendimento das necessidades de saúde da população brasileira, pelo enfrentamento dos seus determinantes sociais com os usos da clínica ampliada, do trabalho em equipe multiprofissional, interativo e participativo, e da produção do cuidado como instrumentos de defesa da vida individual e coletiva, o que imputa a responsabilidade de que façamos dela uma estratégia que dê certo; uma proposta importante na mudança de modelos que procuram contemplar os princípios e diretrizes do sistema de saúde vigente no país. 
A incorporação da proposta do apoio matricial e dos núcleos de saúde da família já está presente e constitui uma boa evidência de andamento desse processo, mas apresenta limites e potências. Há problemas de entendimento da proposta, da predominância de ação biologicista e curativa de alguns profissionais e dos próprios limites em relação à não resolução completa dos problemas da população. Ao mesmo tempo, a integração entre os profissionais possibilita conversas conjuntas, a pactuação de ações, o trabalho interdisciplinar e a construção de projetos terapêuticos em comum, mas esbarra no forte contingenciamento da demanda.

A importância de entender como se dá o processo de implementação isolada do contexto em que se encontra presente, ou a partir da dissociação entre campo e núcleo profissionais parece-nos reducionista. Diante da complexidade do trabalho na APS, tal raciocínio se torna ainda mais inviável, e implica considerar pelo menos três questões cruciais, reveladas pela experiência vivencial dos autores.

Primeiro, que as profissões incluídas como 'apoiadoras' necessitam de construção/reconstrução de identidades que permitam facilitar o entendimento e a aplicação de novas perspectivas e ampliação do campo de valores da sua prática profissional, historicamente construída em profunda alienação das pessoas a que/quem ela se destina. As recentes experiências em serviço, formação e pesquisa são espaços de construção e desconstrução dessa identidade. O sucesso da proposta depende de muitos fatores, porém a busca pela forte conexão entre os serviços de saúde (os profissionais), a população, a gestão e a intersetorialidade deve ser incessante.

Segundo, impõe-se refletir sobre a questão da demanda, para além de compreender e explicar o que a fez aparecer. A demanda aparente e a oferta existente geralmente estão condicionadas pelas práticas do modelo médico biológico-hegemônico, em que as causas de característica orgânica se sobrepõem aos demais fatores que influenciam o processo saúde-doença do indivíduo e da coletividade. A esta influência se soma a lógica de organização da atenção à saúde que dificulta a escuta, o acolhimento e a compreensão do sentido social do sofrimento e adoecimento.

A busca do usuário pelo serviço de saúde se dá por meio da percepção, muitas vezes subjetiva, do que o serviço possa lhe ofertar e de como resolver o seu problema. Em sua grande maioria, os profissionais de saúde têm grande dificuldade de 'traduzir' essa agenda porque as queixas podem estar somatizadas, tendendo a ser patologizadas ou, ainda, adjetivadas de 'recorrentes' e denominando de poliqueixosos àqueles que apresentam condições crônicas de saúde, de causas diversas, em que a duração da doença é longa ou indefinida, o diagnóstico ou prognóstico são usualmente incertos.

Com a inserção do apoio e a oferta de novas ações, esses pacientes retornaram mais ao serviço, o que causou uma 'sensação' de aumento de 
demanda. A partir do momento em que outros profissionais são incorporados para acolher essa demanda, novas questões se revelam importantes no cuidado, mesmo quando o olhar é biológico: a demanda se amplifica ainda mais, visto que não se espera pela chegada ao serviço, e se adota a busca ativa, possível de ser estendida no território adscrito pelo serviço. É esta ênfase nos sujeitos e nos modos de se relacionarem com a vida que traz contribuições para ampliar a compreensão social da demanda e ofertar práticas de integralidade em saúde mais adequadas às demandas e necessidades, recompondo o arco de interfaces entre campo de práticas e núcleos profissionais envolvidos.

Finalmente, mas não por último, a discussão do trabalho em equipe como pressuposto e como dispositivo da interdisciplinaridade e de intersubjetividade. $\mathrm{O}$ aspecto interdisciplinar pressupõe transitar em dois campos: o técnico e o interpessoal, isto é, o trabalho interdisciplinar envolve a 'competência profissional', ligada ao desempenho com base nos conhecimentos técnicos de cada membro da equipe, e a 'competência interpessoal', entendida como a habilidade de se relacionar com outras pessoas. Por essa bipolaridade situacional, no trabalho em saúde deve existir uma produção singular que institua espaços dialógicos com formação de compromisso e construção de contratos. Isto significa que seguir com radicalidade os princípios da ESF é apostar que a interdisciplinaridade pelo trabalho das equipes seja elemento-chave para a busca permanente de comunicação, a troca de experiências e conhecimentos entre os integrantes da equipe, e destes com o saber popular do ACS. Mas quanto estamos prontos para fazê-lo?

Apesar dos limites deste relato sobre uma experiência municipal, entendemos que essa singularidade possa ter semelhanças com outras experiências brasileiras que estão em desenvolvimento. Além disso, espera-se que estudos de experiência possam contribuir na qualificação da implantação do Nasf nos municípios, ao propiciar subsídios sobre a organização, o planejamento e a execução do matriciamento em cada local. O debate está aberto.

\section{Colaboradores}

Aline Barreto de Almeida Nordi participou de todas as etapas de planejamento, desenvolvimento, execução do trabalho, elaboração e revisão do artigo. Geovani Gurgel Aciole orientou o planejamento, a realização e a avaliação do trabalho e a revisão final do artigo. Não há conflitos de interesse. 
Resumen El trabajo aquí presentado resultó de la investigación documental, entrevistas semiestructuradas y grupo focal con los equipos de salud, los apoyadores residentes y la gestión de la atención básica sobre la experiencia de articulación entre los equipos de apoyo matricial y referencia en unidades de salud de la familia, en el contexto de la reformulación del modelo asistencia en implantación en un municipio del interior paulista, en el primer semestre de 2009. Los autores reflexionaron sobre la experiencia en base a tres dimensiones: la comprensión inicial de la propuesta, el cotidiano del trabajo y los impactos en el proceso de trabajo de apoyo matricial. Se observó que el apoyo matricial presentó problemas de comprensión de la propuesta y enfrentó la predominancia de prácticas curativas biologicistas y límites con relación a la solución de los problemas de la población. La integración entre los profesionales permitió pactos conjuntos, el trabajo interdisciplinario y la construcción de proyectos terapéuticos comunes, ofreciendo perspectivas promisoras. Esperamos que estos hallazgos contribuyan a las actuales discusiones sobre la planificación y la gestión del apoyo matricial en el sistema local de salud.

Palabras clave Estrategia Salud de la Familia; atención primaria de la salud; actitud del personal de la salud; promoción de la salud; salud pública.

\section{Notas}

${ }^{1}$ Instituto de Ensino e Pesquisa do Hospital Sírio-Libanês, São Paulo, Brasil.

<alinealmeida7@yahoo.com.br>

Correspondência: Rua Francisco Falvo, 248, quadra 2, casa 39, condomínio Bosque de São Carlos, CEP 13565-910, São Carlos, São Paulo, Brasil.

2 Universidade Federal de São Carlos, Programa de Pós-Graduação em Gestão da Clínica, São Carlos, São Paulo, Brasil.

<geovani.gurgel@gmail.com>

\section{Referências}

ALVES, Vania S. Um modelo de educação em saúde para o Programa Saúde da Família: pela integralidade da atenção e reorientação do modelo assistencial. Interface: Comunicação, Saúde e Educação, Botucatu, v. 9, n. 16, p. 39-52, 2005.

AYRES, José R. C. M. Sujeito, intersubjetividade e práticas de saúde. Ciência \& Saúde Coletiva, Rio de Janeiro, v. 6, n. 1, p. 63-72, 2001.
AYRES, José R. C. Cuidado e reconstrução das práticas de saúde. Interface: Comunicação, Saúde e Educação, Botucatu, v. 8, n. 14, p. 73-92, 2004.

BRASIL. Ministério da Saúde. Secretaria de Atenção à Saúde. Departamento de Atenção Básica. Política Nacional de Atenção Básica. Brasília, DF: Ministério da Saúde, 2012. Disponível em: <http://189.28.128.100/dab/ 
docs/publicacoes/geral/pnab.pdf $>$. Acesso em: 13 mar. 2013.

BRASIL. Ministério da Saúde. Portaria GM n. 154, de 24 de janeiro de 2008. Cria os núcleos de apoio à saúde da família-Nasf. Diário Oficial da União, Brasília, DF, 25 jan. 2008. Seção 1, página 47-49. Disponível em: $<$ http://bvsms.saude.gov.br/bvs/saudelegis/ gm/2008/prt0154_24_01_2008.html>. Acesso em: 15 abr. 2009.

BREVIDELLI, Maria M.; DE DOMENICO, Edvane B. L. Trabalho de conclusão de curso: guia prático para docentes e alunos da área da saúde. São Paulo: Iátria, 2006.

CAMPOS, Carlos Eduardo A. O desafio da integralidade segundo as perspectivas da vigilância da saúde e da saúde da família. Ciência \& Saúde Coletiva, Rio de Janeiro, v. 8, n. 2, p. 569-584, 2003.

CAMPOS, Gastão W. S. Clínica e saúde coletiva compartilhadas: teoria Paideia e reformulação ampliada do trabalho em saúde. In: CAMPOS, Gastão W. S. et al. (orgs.). Tratado de saúde coletiva. São Paulo: Hucitec; Rio de Janeiro: Editora Fiocruz, 2007. p. 41-80.

CAMPOS, Gastão W. S; DOMITTI, Ana Carla. Apoio matricial e equipe de referência: uma metodologia para gestão do trabalho interdisciplinar em saúde. Cadernos de Saúde Pública, Rio de Janeiro, v. 23, n. 2, p. 399-407, 2007.

CARDOSO, Cláudia L. A inserção do psicólogo no Programa Saúde da Família. Psicologia: Ciência e Profissão, Brasília, v. 22, n. 1, p. 22-29, 2002.

CECCIM, Ricardo B. Equipe de saúde: a perspectiva entre-disciplinar na produção dos atos terapêuticos. In: PINHEIRO, Roseni; MATTOS, Ruben A. (orgs.). Cuidado: as fronteiras da integralidade. São Paulo: Hucitec, 2004. p. 259-305.

CRUZ NETO, Otávio. O trabalho de campo como descoberta e criação. In: MINAYO, Maria C. S. (org.). Pesquisa social: teoria, método e criatividade. 23. ed. Petropólis: Vozes, 2004. p. 51-66.

ESCOREL, Sarah et al. O Programa de Saúde da Família e a construção de um novo modelo para a atenção básica no Brasil. Revista Panamericana de Salud Pública, Washington DC, v. 21, n. 2, p. 164-176, 2007.

ESCÓSSIA, Liliana. O coletivo como plano de criação na saúde pública. Interface: Comunicação, Saúde e Educação, Botucatu, v. 13, supl. 1, p. 689-694, 2009.

FRANCO, Túlio B.; MERHY, Emerson E. A produção imaginária da demanda e o processo de trabalho em saúde. In: PINHEIRO, Roseni; MATTOS, Ruben A. (orgs.). Construção social da demanda: direito à saúde, trabalho em equipe, participação e espaços públicos. Rio de Janeiro: Cepesc/Uerj, Abrasco, 2005. p. 181-194.

LACERDA, Alda; VALLA, Victor V. Um outro olhar sobre a construção social da demanda a partir da dádiva e das práticas de saúde. In: PINHEIRO, Roseni; MATTOS, Ruben A. (orgs.). Construção social da demanda: direito à saúde, trabalho em equipe, participação e espaços públicos. Rio de Janeiro: Abrasco, 2005. p. 279-291.

MACHADO, Felipe R. S. et al. As novas formas de cuidado integral nos espaços públicos de saúde. In: PINHEIRO, Roseni; MATTOS, Ruben A. (orgs.). Cuidado: as fronteiras da integralidade. Rio de Janeiro: Uerj/IMS, Abrasco, 2004. p. 57-74.

MATTOS, Ruben A. A integralidade na prática (ou sobre a prática da integralidade). Cadernos de Saúde Pública, Rio de Janeiro, v. 20, n. 5, p. 1.411-1.416, 2004.

MATTOS, Ruben A. Os sentidos da integralidade: algumas reflexões acerca de valores que merecem ser defendidos. In: PINHEIRO, Roseni; MATTOS, Ruben A. (orgs.). Os sentidos da integralidade na atenção e no cuidado à saúde. Rio de Janeiro: Uerj/IMS, Abrasco, 2001. p. 39-64 
MINAYO, Maria Cecília S. O desafio do conhecimento: pesquisa qualitativa em saúde. 9. ed. São Paulo: Hucitec, 2006.

MINAYO, Maria Cecília S. et al. Métodos, técnicas e relações em triangulação. In: MINAYO, Maria C. S. et al (orgs.). Avaliação por triangulação de métodos: abordagem de programas sociais. Rio de Janeiro: Editora Fiocruz, 2005.

PINHEIRO, Roseni; GUIZARDI, Francini L. Cuidado e integralidade: por uma genealogia de saberes e práticas no cotidiano. In: PINHEIRO, Roseni; MATTOS, Ruben A. (orgs.). Cuidado: as fronteiras da integralidade. Rio de Janeiro: Uerj/IMS, Abrasco, 2006. p. 21-36.

PINHEIRO, Roseni; LUZ, Madel T. Práticas eficazes x modelos ideais: ação e pensamento na construção da integralidade. In: PINHEIRO, Roseni; MATTOS, Ruben A. (orgs.). Construção da integralidade: cotidiano, saberes e práticas de saúde. Rio de Janeiro: Uerj/IMS, Abrasco, 2003. p. 7-34.

SANTOS, Antonio R. Metodologia científica: a construção do conhecimento. 5. ed. Rio de Janeiro: DP\&A, 2002.
SÃO CARLOS. Prefeitura. Secretaria Municipal de Saúde. Disponível em: <www. saocarlos.sp.gov.br>. Acesso em: 28 set. 2007.

SCHWANDT, Thomas A. Três posturas epistemológicas para a investigação qualitativa. In: DENZIN, Norman K; LINCOLN, Yvonna (orgs.). O planejamento da pesquisa qualitativa: teorias e abordagens. 2. ed. Porto Alegre: Artmed, 2006.

TURATO, Egberto R. Tratado da metodologia da pesquisa clínico-qualitativa. Petrópolis: Vozes, 2003.

SILVA, Inês Z. Q. J.; TRAD, Leny A. B. O trabalho em equipe no PSF: investigando a articulação técnica e a interação entre os profissionais. Interface: Comunicação, Saúde e Educação, Botucatu, v. 9, n. 16, p. 25-38, set.2004-fev.2005.

Recebido em 27/04/2015

Aprovado em 14/07/2016 